\title{
The History of Wretched Subjects
}

\section{Otto Neugebauer}

Editor's note: Otto Neugebauer was for many years Professor of the History of Mathematics at Brown University, RI. His prolific output included The Exact Sciences in Antiquity (Brown University, 1957) and the three volume A History of Ancient Mathematical Astronomy, (Springer Verlag, 1975). Sadly he died in 1992. The following text, which is reproduced with permission from Isis, vol. 42, June 1951 is a classic statement of the importance of the history of astrology in the history of ideas.

In the last issue of Isis (vol. 41, 125-126, p.374) there is a short review by Professor Sarton of a recent publication by E.S.Drower of the Mandean 'Book of the Zodiac' which is characterized by the reviewer as 'a wretched collection of omens, debased astrology and miscellaneous nonsense'. Because this factually correct statement ${ }^{1}$ does not tell the whole story, I want to amplify it by a few remarks to explain to the reader why a serious scholar might spend years on the study of wretched subjects like ancient astrology.

The great Belgian historian and philologist, Franz Cumont, in August 1898 signed the preface to the first volume of the Catalogus Codicum Astrologorum Graecorum, the twelfth volume of which is now in preparation. The often literal agreement between the Greek texts and the Mandean treatises requires the extension of Professor Sarton's characterization to an enterprise which has enjoyed the wholehearted and enthusiastic support of a great number of scholars of the very first rank. They all labored to recover countless wretched collections of astrological treatises from European libraries, and they succeeded in giving us an insight into the daily life, religion and superstition, and astronomical methods and cosmogonic ideas of generations of men who had to live without the higher blessings of our own scientific era.

To the historian of science the transmission of ideas is rightly one of his most important problems. Astrological lore furnishes us one of the most convincing proofs for the transmission of Hellenistic astronomy to India; astrological manuscripts help us to estimate more accurately the combination of Syriac, Arabic, Hindu, and Greek sources in the building

Otto Neugebauer, 'On the History of Wretched Subjects', Culture and Cosmos, Vol. 1, no. 2, Autumn/Winter 1997, pp. 3-4. www.CultureAndCosmos.org

6 On the History of Wretched Subjects 
up of Islamic science. No Arabic astronomer can be fully understood without a thorough knowledge of astrological concepts. The only hope of obtaining a few glimpses of the astronomical methods of the time of Hipparchus rests in the painstaking investigation of wretched writers like Vettius Valens or Paulus Alexandrinus. Six large volumes of miscellaneous nonsense were published by Professor Thorndike and have become a treasured tool for the study of Mediaeval scientific literature. And the history of the art and philosophy of the Renaissance has gained immensely from the researches carried out by the Warburg Institute on the astrology of preceding periods.

The book by Mrs. Drower is only one modest contribution within the larger task of research in the history of the civilization of the Near East. The difficulties of the problems involved are by far greater than in the case of Greek or Latin texts with their so much better known terminology and background. We have to thank Mrs. Drower for exposing a new source which may one day furnish the missing link in the transmission of doctrines which have left their imprint in almost all phases of Mediaeval learning, Medicine, Botany, Chemistry, etc.

All these facts are, of course, well known to Professor Sarton. But when the recognized dean of the History of Science disposes of a whole field with the words 'the superstitious flotsam of the Near East,' he perhaps does not fully realize how much he is contributing to the destruction of the very foundations of our studies: the recovery and study of the texts as they are, regardless of our own tastes and prejudices.

\section{Reference}

1. The classification under 'Babylonia and Assyria' is misleading because Mandean astrology belongs to the Islamic, and thus ultimately Hellenistic, civilization. 